\section{A new regional scheme for psychiatric registrars in South East Thames}

\section{DeAR Sirs}

We thought we should let you know that the arrangements outlined in the account of our new scheme (Psychiatric Bulletin, 1991, 15, 552-554) have been put in jeopardy by changes in regional administration and policy since the article was accepted for publication.

South East Thames have agreed a policy to devolve as much as possible to what they refer to as 'Units', which may be in Trusts or in District Managed Organisations. Also, they are engaged in the task of setting the Regional Dean's budget which is supposedly to cover the costs of postgraduate education. We understand that all regions are engaged in these exercises.

Problems for a regional scheme seem inevitable from a deliberate policy to so devolve responsibility, and at present we do not know whether or not it will be possible to preserve this scheme in an educationally acceptable way. The regional education budget appears to be being set to cover Postgraduate Centres in Districts and relatively little else, so that the hope expressed in the last sentence of our article ('adequate funding for these activities for the first time') seems likely to be a pious one.

Problems like these seem inevitable in all regions. Not only is local vigilance once again required, but the College may need to make major efforts to ensure the preservation of rotational training scheme structures. One local good sign is that our region has acknowledged the existence and importance of regional training committees concerned with registrar and senior registrar training.

Guy's Hospital

London Bridge, SEI 9RT managers are certainly not. 'Psychotherapist' means any individual who has had a psychotherapy training, although that training is not yet a statutory requirement before using the title. 'Consultant' is being increasingly used by other professional groups, outside as well as inside health care, and its implication is now more of a role than a title implying training, status or carrying responsibility.

At a recent College meeting between psychotherapy trainers and trainees, there was a realisation that we need to start learning the new 'NHS language' to define, describe and publicise just what it is that we can offer by virtue of our medical and psychiatric backgrounds. Patients with somatic complaints or suicidal symptoms immediately come to mind, as does communication with other doctors and the ability to carry ultimate clinical and medical responsibility. The authority and willingness to not prescribe medication is becoming increasingly important as public disillusionment with the prescription of psychotropic drugs increases. Another area to which we could actively contribute is preventative work: as Obholzer (Psychiatric Bulletin, 1989, 13, 432-434) states, "Raising awareness of the factors that generate psychological disturbance is a better use of our resources than concentration solely on the provision of psychotherapy services".

That the term 'Consultant Psychotherapist' has lost its medical roots is of particular concern because purchasers (be they GPs or Directors of Public Health) and employers will not see that we have something to offer that justifiably costs more than private therapy or NHS treatment with non-medical therapists. I wonder if the term 'Consultant Psychiatrist in Psychotherapy', which has a tidy parallel with 'Consultant Psychiatrist with Special Responsibility in Psychotherapy', would be a better one with which to market ourselves?

Uffculme Clinic

Rex Haigh

Queensbridge Road

Moseley, Birmingham B13 $8 Q D$

\section{What's in a name?}

\section{DeAR SirS}

Since taking up my post last February $I$ have been referred by learned and lay colleagues by a variety of titles, including Consultant Geriatrics/Psycho Unit, Consultant Psycho Unit, Consultant in EMI Services, Consultant Psychogeriatrician, Consultant Psychiatric/Geriatric, Consultant in Psychiatry of Elderly, Consultant in Old Age Psychiatry (my preference). This confusion is clearly not an idiocyncrasy of Coventrians as judged by experiences of other colleagues. I wonder if the College can take a lead in 